\title{
Study of mining tailings geotechnical parameters obtained from SCPTu tests carried on dry and saturated layers
}

\author{
Helena P. Nierwinski ${ }^{1, *}$, Marcelo Heidemann ${ }^{1}$, Laura A. Lavalle ${ }^{2}$, and Bruna Sell ${ }^{1}$ \\ ${ }^{1}$ Federal University of Santa Catarina, Joinville School of Technology, Dona Francisca St. 8300, 89219-600, Joinville, Brazil. \\ ${ }^{2}$ Universidad de la Salle, Carrera 2 \# 10-70, Bogota, Colombia.
}

\begin{abstract}
The correct interpretation of in situ and laboratory test results is an important step in the design of mining tailing containment structures. This study aims to analyze the Seismic Cone Penetration Test (SCPTu) results obtained into a mining tailing reservoir composed of two material layers: a thick-dry and a ticksaturated. It is possible to observe that in a same tailing reservoir, the CPTu test interpretation can lead to a classification of each layer as a different soil with specific behavior and properties. This condition demonstrates that tailings with intermediate permeability $\left(10^{-5} \mathrm{~m} / \mathrm{s}<\mathrm{k}<10^{-8} \mathrm{~m} / \mathrm{s}\right)$ may present partial drainage conditions during a standard cone penetration test $(\mathrm{CPTu})(\mathrm{v}=20 \mathrm{~mm} / \mathrm{s})$, if saturated conditions are verified. The effects of partial drainage can affect test results, and can induce to errors in the prediction of soil behavior and geotechnical parameters. To evaluate the possible effects of partial drainage, in situ test results were compared to laboratory tests results. It was possible to verify that estimated behavior of dry layers, obtained from in situ tests results, present more similarity to the results from laboratory tests. Probably, the partial drainage effects verified through the interpretation of dissipation tests, distorted the estimated behavior of the saturated layer material.
\end{abstract}

\section{Introduction}

Mining activity plays a key role in Brazil's economy (IBRAM 2018 [1]) and several other countries. Over the years, technological progress has promoted an increase in the productivity of this sector. However, concomitant with the increase in commercial value products' extraction, the generation of mining tailings growth. According to the Institute of Applied Economic Research (IPEA 2012 [2]), in Brazil, the tailings production reached 290 million tons in 2005 . There is a prospect of production of 684 million tons in 2030, implementing innovations in this sector.

One of the major challenges related to the high production of mining waste is how these materials must be stored. Due to the presence of chemical elements from the beneficiation process, the environmental agencies require an environmentally correct disposition, which occurs through raising dams, normally due to economic and operational advantages. Recent episodes of Brazilian tailing dam failures (Morgenstern et al. 2016 [3]; Robertson et al. 2019 [4]) impose dam design standards reformulation and an accurate evaluation of tailing geotechnical parameters.

For a correct definition of geotechnical design parameters, one of the main requirements is linked to the definition of the type of response expected by the material about the imposed loads. The design parameters can be defined in a drained or undrained condition. If the material presents low permeability, like clay, it does not allows water left immediately, and the design parameter will be defined on undrained conditions. On the other hand, materials that present high permeability, as granular soils, allows fast drainage, and the design parameters will be defined on drained conditions (Lambe and Whitman 1969 [5]).

Most of the mining tailings, in turn, are silty materials with low or null plasticity. According to previous studies, the permeability coefficient of these materials is in the intermediate range, which is $10^{-5} \mathrm{~m} / \mathrm{s}<k<10^{-8} \mathrm{~m} / \mathrm{s}$ (Schnaid et al. 2005 [6]; Dienstmann et al. 2018 [7]). Doubts surround the design parameters defined in this situation, and there are no consensual guidelines for correct testing and data interpretation, which can affect the design parameters evaluation.

According to Djong and Randolph (2012) [8], the results of a standard cone penetration test $(\mathrm{v}=20 \mathrm{~mm} / \mathrm{s})$, when conducted in intermediate permeability materials, can be affected by partial drainage around the cone during penetration. Several studies support this occurrence analyzing the CPTu test results with variable penetration velocity (Randolph and Hope 2004 [9]; Kim et al. 2008 [10]) and achieving full drainage conditions only at low penetration velocities and completely undrained conditions at high penetration velocities.

In this way, this paper aims to investigate the influence of drainage conditions on the prediction of mining tailings behavior based on SCPTu tests conducted on a thick-dry and a tick-saturated layer of the same tailings. In dry conditions, there is no influence of partial drainage on

\footnotetext{
* Corresponding author: helena.paula@ufsc.br
} 
penetration test results. However, the interpretation of these results can be compared to the test results conducted on a saturated layer to investigate the partial drainage influence.

\section{Investigation campaign}

To achieve this research's objective, the results of a geotechnical investigation campaign carried out in a Brazilian deposit of copper mining tailings were analyzed. The tailing characterization was made using characterization laboratory tests and in situ SCPTu with dissipation tests.

\subsection{Copper tailing laboratory characterization}

Figure 1 presents the grain distribution of the studied copper mining tailing. It is possible to verify that the copper tailing is composed predominantly by intermediate particle size, that is, a major amount of particles present silt and fine sand size, according to ASTM soil classification.

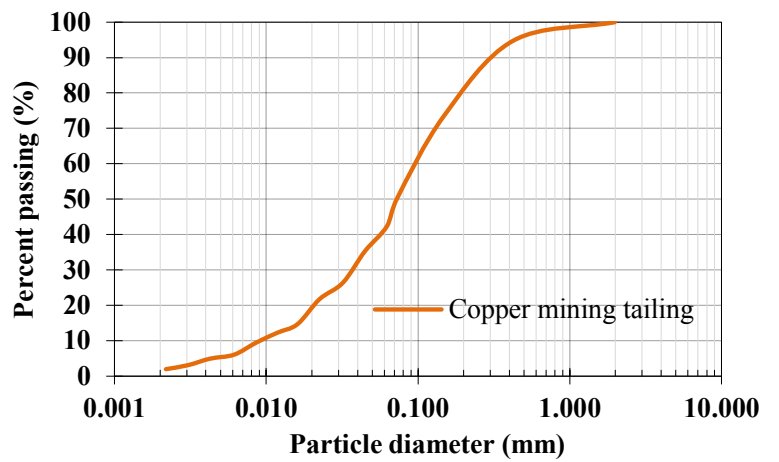

Fig. 1. Copper mining tailing particle distribution

The analyzed tailing does not present plasticity and can be classified as ML (low plasticity silt) according to the Unified Soil Classification System (USCS). The specific gravity is equal to 2.80 , and the natural water content of the material from saturated layers is about $54 \%$. The maximum dry unit weight and optimum moisture for standard Proctor compaction effort is $16.9 \mathrm{kN} / \mathrm{m}^{3}$ and $15.3 \%$, respectively.

As the copper mining tailings do not present plasticity, the extraction of samples by conventional methodologies, such as the Shelby sampler, becomes ineffective. Thus, to assess the permeability and shear strength of the tailings reconstituted samples with $90 \%$ of the maximum dry unit weight and optimum moisture for standard Proctor compaction effort were used.

The permeability coefficient obtained from variable load permeability tests was about $1.5 \times 10^{-6} \mathrm{~m} / \mathrm{s}$, at $20^{\circ} \mathrm{C}$. The friction angle was obtained through $\mathrm{CU}$ triaxial tests, and the average values are in the order of $35^{\circ}$, and the cohesion intercept is null. Even without carrying out drained tests, the value of the material state parameter $(\psi)$ was defined by the construction of the critical state line (CSL) based on the ultimate conditions of loading and deformation obtained from $\mathrm{CU}$ triaxial tests. This parameter is fundamental to the evaluation of the potential for the occurrence of liquefaction in tailing reservoirs, which has been one of the main causes of ruptures in such deposits (Morgenstern et al. 2016 [3]; Robertson et al. 2019 [4]).

\subsection{In situ testing on copper tailing}

The research in situ campaign includes 3 vertical SCPTu tests with dissipation tests. The SCPTu test results' evaluation demonstrates that the deposit is composed of dry layers and saturated layers with distinct thicknesses, as indicated in Table 1. The seismic velocity measurements were obtained every meter along with the depth.

Table 1. SCPTu test campaign summary information.

\begin{tabular}{c|c|c|c|c}
\hline Test & $\begin{array}{c}\text { Total } \\
\text { depth }(\mathbf{m})\end{array}$ & $\begin{array}{c}\text { Dry } \\
\text { layer } \\
(\mathbf{m})\end{array}$ & $\begin{array}{c}\text { Saturated } \\
\text { layer }(\mathbf{m})\end{array}$ & $\begin{array}{c}\mathbf{N}^{\mathbf{0}} \text { of } \\
\text { dissipation } \\
\text { tests* }\end{array}$ \\
\hline SCPTu 1 & 45 & 15 & 30 & 5 \\
SCPTu 2 & 35 & 28 & 7 & 1 \\
SCPTu 3 & 12 & 5 & 7 & 2 \\
\hline \multicolumn{2}{r}{ *on saturated layer }
\end{tabular}

Figure 2 demonstrates a typical result of cone tip resistance $\left(q_{t}\right)$ and porepressure measurements $\left(u_{2}\right)$ (SCPTu 1) and the indication of the dry and saturated layer studied in this case.

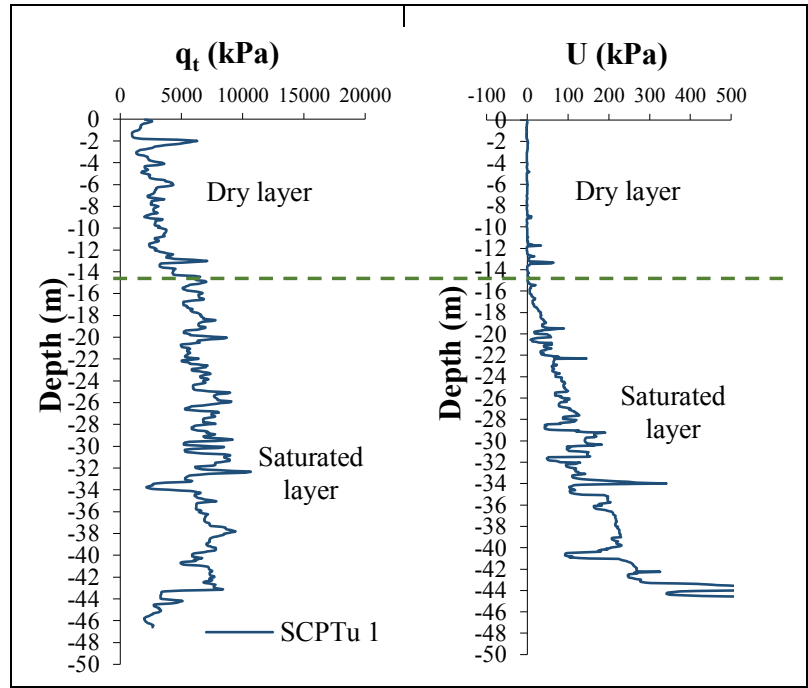

Fig. 2. Cone tip resistance $\left(q_{t}\right)$ and porepressures $\left(u_{2}\right)$ along depth for SCPTu 1

Figure 3 presents a typical result from dissipation tests conducted on saturated layers. From the interpretation of the dissipation test results, it was possible to estimate the values of vertical consolidation coefficient $\left(c_{v}\right)$ and vertical permeability coefficient $(k)$. The $c_{v}$ values vary from $5 \times 10^{-6} \mathrm{~m}^{2} / \mathrm{s}$ to $1.5 \times 10^{-5} \mathrm{~m}^{2} / \mathrm{s}$. The estimated values of the vertical permeability coefficient vary from $1.3 \times 10^{-5} \mathrm{~m} / \mathrm{s}$ to $9.2 \times 10^{-7} \mathrm{~m} / \mathrm{s}$. 


\section{SCPTu results interpretation on dry and saturated layers}

Given the influence of partial drainage effects on measurements of cone tests on mining tailings, the first step of this study consists of verifying the response of a combination of measurements conducted on dry and saturated tailing to predict the its behavior. The results obtained for each layer will be compared to the laboratory characterization to evaluate the partial drainage effects.

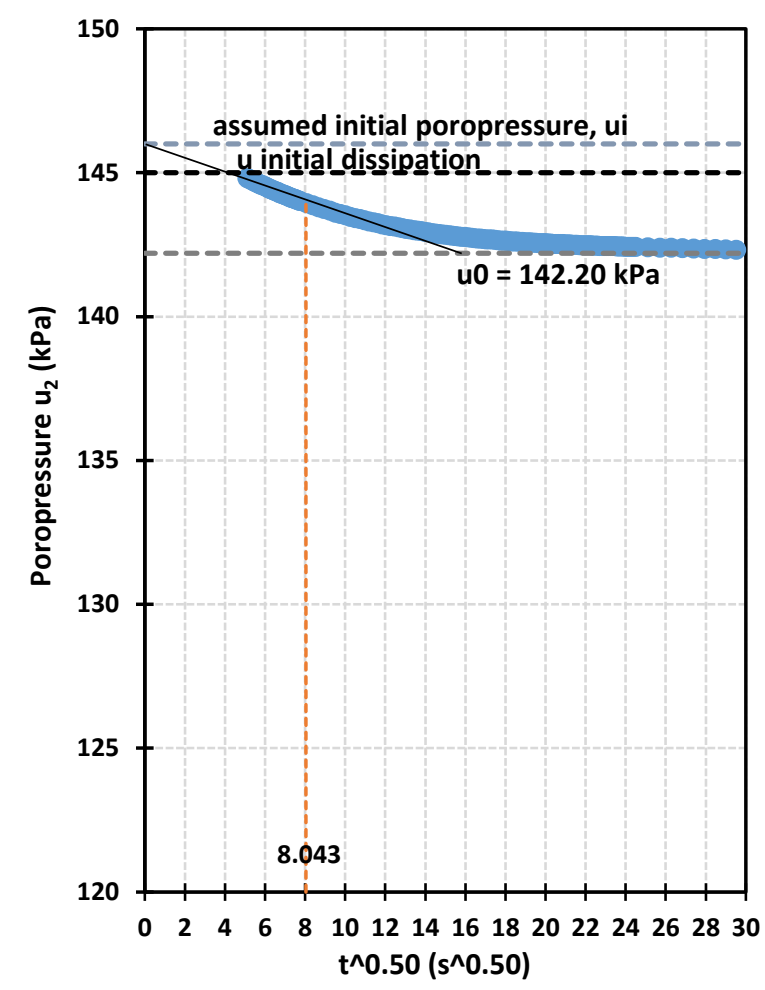

Fig. 3. Dissipation test typical result, where $u_{0}$ is the hydrostatic pressure and $u_{i}$ is the porepressure at the beginning of dissipation test

As the cone test does not allow soil sampling, the simplest way to identify the behavior and classify the subsoil's different layers is by using the Soil Behavior Type Classification Chart (SBT). Robertson (1990) [11] presents charts based on normalized data (Eq. 1 to Eq. 3) of cone tip $\left(q_{t}\right)$, porepressure $\left(u_{2}\right)$, and sleeve friction $\left(f_{s}\right)$, allowing the soil behavior classification in nine different classes, as indicated on Table 2.

$$
\begin{aligned}
Q_{t} & =\frac{q_{t}-\sigma_{v 0}}{\sigma^{\prime} v 0} \\
B_{q} & =\frac{\left(u_{2}-u_{0}\right)}{\left(q_{t}-\sigma_{v 0}\right)} \\
F_{r} & =\frac{f_{s}}{\left(q_{t}-\sigma_{v 0}\right)} \cdot 100 \%
\end{aligned}
$$

where $\sigma_{v 0}$ and $\sigma_{v 0}^{\prime}$ are the total and effective vertical stresses, respectivelly, and $u_{0}$ is the hidrostatic pressure. $Q_{t}, B_{q}$ and $F_{r}$ are the normalized measurements.

Considering the shear wave measurements from SCPTu tests, the soil behavior can also be predicted by the chart proposed by Robertson et al. (1995) [12] that is based on normalized cone resistance $\left(Q_{t}\right)$ and the ratio of small strain shear modulus $\left(G_{0}\right)$ to cone resistance $\left(G_{0} / q_{t}\right)$. The $G_{0}$ can be defined directly by shear wave velocities, as exposed by Equation 4 .

$$
G_{0}=\rho \cdot V_{s}^{2}
$$

where $\rho$ is the mass density (natural specific weight divided by the gravity acceleration) and $V_{s}$ is the shear wave velocity.

According to Lunne et al. (1997) [13] the chart based on $G_{0}$ can be used to identify "unusual" soils such as highly compressible sands and can be useful to analysis on mining tailings behavior.

Table 2. Behavior soil classes for SBT charts from Robertson (1990) [11]

\begin{tabular}{c|c}
\hline Chart zone & Soil Type \\
\hline 1 & Sensitive, fine grained \\
2 & Organic soils - peat \\
3 & Clays - clay to silty clay \\
4 & Silt mixtures, clayey silt to silty clay \\
5 & Sand mixtures, silty sand to sand silty \\
6 & Sands, clean sands to silty sands \\
7 & Gravelly sand to sand \\
8 & Very stiff sand to clayey sand \\
9 & Very stiff fine grained \\
\hline
\end{tabular}

Figure 4 presents the copper mining tailing behavior classification based on normalized cone resistance $\left(Q_{t}\right)$ versus porepressure parameter $\left(B_{q}\right)$. It is observed that there is a tendency for the combination of results of tests carried out on the dry layer to occupy a region different from that occupied by the combination of data from tests carried out on the saturated layer. There is a clear dispersion of the graph's data, which is typical of the interpretation based on in situ tests. However, it appears that the results from the dry layer indicate a material with behaviour typical of granular soils, while the results from the saturated layer lies on the area that corresponds to clay behavior.

Comparing the results obtained in this classification with the results from laboratory tests, it can be inferred that the behavior verified for the dry layer is much closer to the behavior defined in the laboratory. Probably the standard driving speed did not allow the complete dissipation of the porepressures caused by the driving, which led to the reading of low values of excess of porepressures but which were already sufficient to promote a reduction in the values of the cone tip resistance and generating intermediate values of $B_{q}$.

According to Schnaid 2009 [14] and Hight et al. 1994 [15], drained conditions are verified for $B_{q}=0$, and undrained conditions can be characterized for $B_{q}>0.6$. Figure 4 shows that the saturated layer's $B_{q}$ values become intermediate values or partial drainage conditions.

Differences in the behavior of dry and saturated layers can also be verified on classification based on $Q_{t}$ and $F_{r}$, 
as demonstrated in Figure 5. Again the position of combined data from dry layers matches more with the results from laboratory tests. The analyses of Figure 5 corroborates with the statement that porepressures developed by cone penetration promotes reduction on cone tip resistance, which causes a reduction in the values of $Q_{t}$ and increases the values of $F_{r}$, leading to a classification related to soils with clayey behavior.

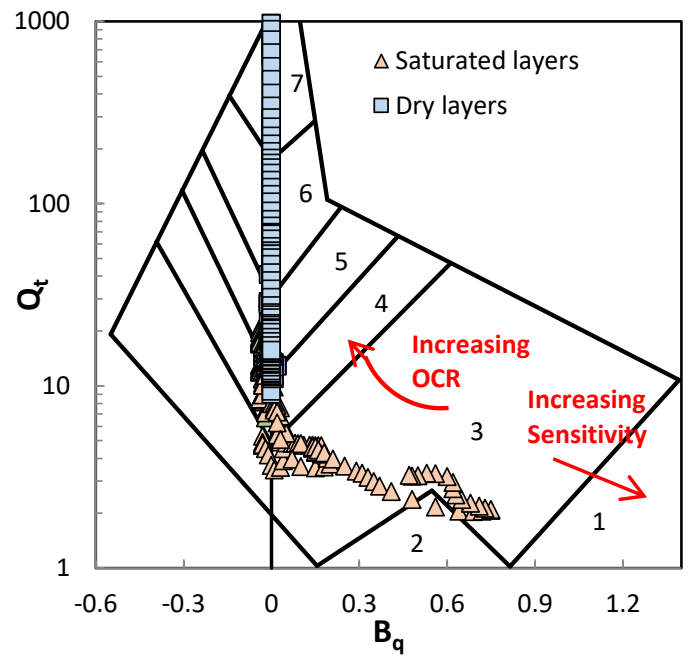

Fig. 4. Soil behavior classification based on normalized resistance $\left(Q_{t}\right)$ and porepressure parameter $\left(B_{q}\right)$

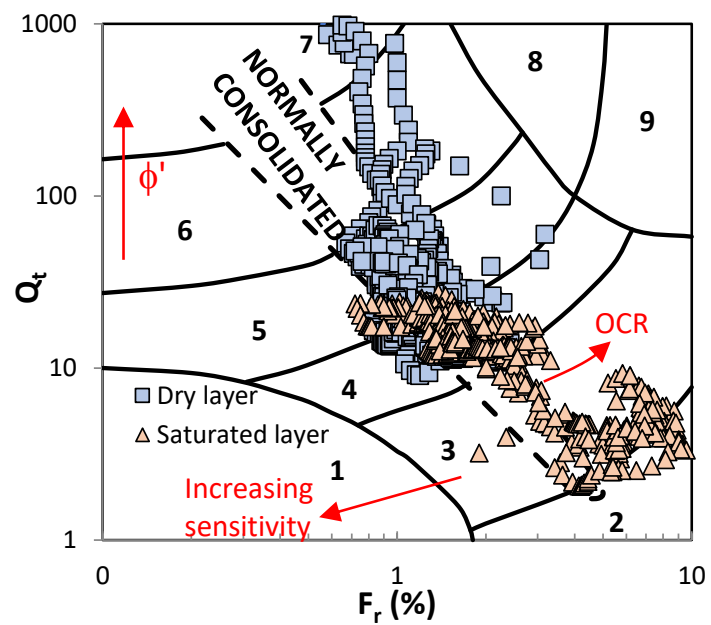

Fig. 5. Soil behavior classification based on normalized resistance $\left(Q_{t}\right)$ and friction parameter $\left(F_{r}\right)$

The tailing behavior was also verified using the combination of small shear modulus and cone tip resistance. Both the stiffness $\left(G_{0}\right)$ and the cone tip resistance $\left(q_{t}\right)$ are controlled (although differently) by void ratio, mean stresses, compressibility, and soil structure. They are, therefore, different functions of the same variables (Schnaid 2005 [16]). As a ratio, these two measurements can be useful in predicting the soil state (Schneider and Moss 2011 [17]; Robertson 2016 [18]. Figure 6 demonstrates these variables' combination to evaluate the behavior of dry and saturated layers of copper mining tailing. The dispersion observed in this scenario appears to be a little smaller than verified on the later graphs. The scatter reduction was probably achieved by combining two parameters that are a function of the same variables, but one captured on a high state of deformations and the other on a low state of deformations. The partial drainage has little or any influence on shear wave measurements, as demonstrates by Nierwinski 2019 [19], however in some depths, the reduction caused by partial drainage on $q_{t}$ values are more evident that make an increase in $G_{0} / q_{t}$ ratio, that combined with the reduction on $Q_{\mathrm{t}}$ values also indicate an inadequate clayey behavior for the material.

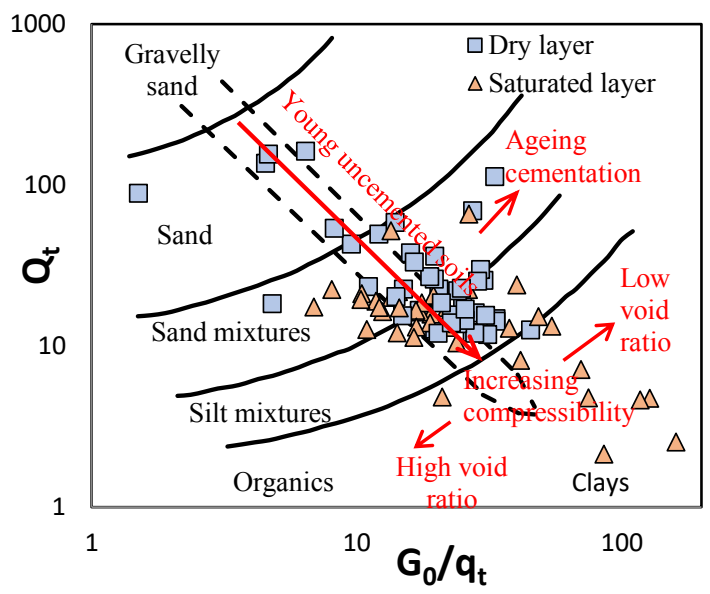

Fig. 6. Soil behavior classification based on normalized resistance $\left(Q_{t}\right)$ and maximum shear modulus and cone tip ratio $\left(G_{0} / q_{t}\right)$

The verification of the influence of the possible occurrence of partial drainage conditions during the cone penetration was also carried out by estimating the material's friction angle through the cone test results and compared with those obtained through laboratory tests. Obviously, laboratory values may have been affected by sample reconstitution. However, they will serve as a comparative criterion.

As copper mining tailings do not have plasticity, the angle of friction may be the parameter used to design containment structures with this material. There are several empirical formulations proposed by the literature to estimate the angle of friction, some derived from the relative density of granular soils $(R D)$ (Bolton 1986 [20]; De Mello 1971 [21]), and another derived directly from the combination of cone tip strength values (Mayne 2006 [22]), such as indicated by the Equations 5 to 7.

$$
\begin{gathered}
\phi^{\prime}=33+\left\{3 \cdot\left[R D\left(10-\ln \sigma^{\prime}{ }_{v 0}\right)-1\right]\right\} \\
\phi^{\prime}=\tan ^{-1}\left(\frac{0.712}{1.49-R D}\right) \\
\phi^{\prime}=\operatorname{arctg}[0.1+0.38 \cdot \log ]\left(\frac{q_{t}}{\sigma^{\prime}{ }_{v 0}}\right)
\end{gathered}
$$

According to Schnaid and Odebrecht (2012) [23], the relative density from cone penetration test can be estimated by using Equation 8.

It is interesting to note that this equation considers the value of the cone tip resistance without correcting the 
porepressure $\left(q_{c}\right)$, which may influence the calculation of the friction angle values in the study's sequence.

$$
R D=-98+66 \cdot \log _{10} \frac{q_{c}}{\left(\sigma^{\prime}{ }_{v 0}\right)^{0.5}}
$$

Figure 7 presents $\phi$ ' values calculated from Equations 5,6 , and 7 for SCPTu 1 and compared to the $\phi^{\prime}$ obtained from $\mathrm{CU}$ triaxial tests conducted on reconstituted samples. It is verified that the $\phi$ ' values estimated from relations with $R D$, derived from peak resistance values not corrected by porepressure, are higher than those obtained by direct correlation with qt values. The values defined in the laboratory are intermediate between the empirical values estimated from the cone test.

There was no considerable difference in the estimated values of $\phi$ ' between the dry and saturated layers. However, disregarding the superficial layer, which possibly influences some dryness, apparently, $\phi$ ' values are slightly lower in the dry layer. They tend to increase along the saturated layer and reduce significantly in the last depths.

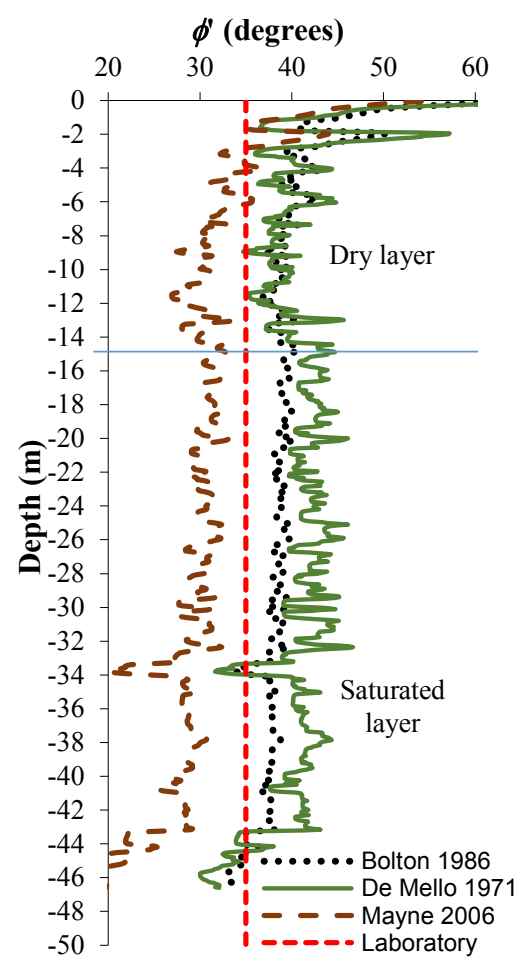

Fig. 7. Friction angles estimated by different formulation from cone tests

Considering the high susceptibility of mining tailings dams to flow liquefaction failures, the state parameter $(\psi)$ is also an important design parameter. There is a formulation proposed by Schnaid and Yu (2007) [24] to access $\psi$ directly from SCPTu tests that were developed for use in sands (Equation 9).

$$
\psi=0.520\left(\frac{p^{\prime}}{p_{a}}\right)^{0.07}+0.180\left(\frac{G_{0}}{q_{t}}\right)
$$

The parameters $p^{\prime}$ and $p_{a}$ are the mean effective stress, and the reference mean effective stress, respectively.

Knowing that copper mining tailings are silty grainsized and considering that Equation 9 uses the $G_{0} / q_{t}$ ratio, that demonstrates a response in terms of behavior classification less influenced by partial drainage in this material, the formulation will be used to verify $\psi$ values along the depth.

Figure 8 demonstrates the $\psi$ values along with depth for SCPTu 1 test. It is possible to verify that the formulation presents $\psi$ similar to that obtained from laboratory tests until $30 \mathrm{~m}$ depth. At greater depths, the values of $\psi$ estimated from the SCPTu test present values higher than the laboratory values. Probably in these depths, the excess of porepressures reduces more the $q_{t}$ values, increasing the $G_{0} / q_{t}$ ratio and increase the value of estimated $\psi$. As presented in the study of Nierwinski 2019 [19], the use of Equation 9 in non-plastic silty soils require the application of a correction on qt values to transform them into totally drained values.

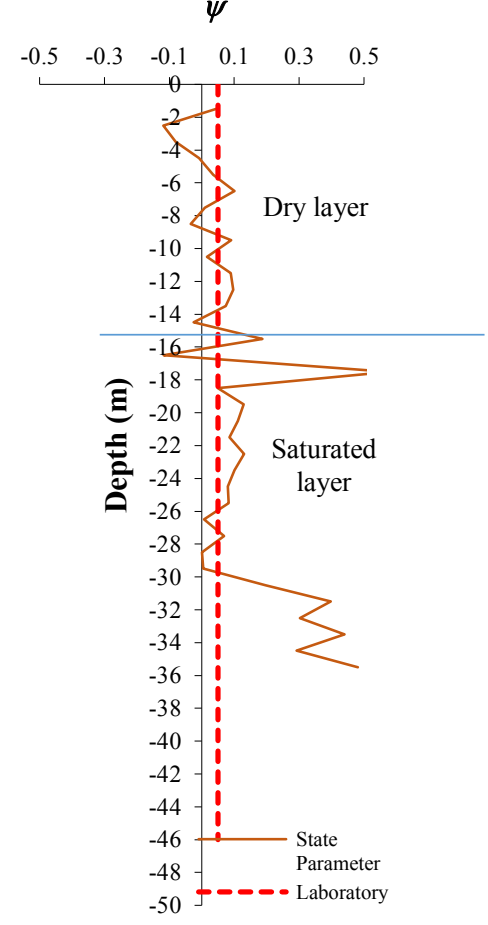

Fig. 8. State parameter estimated from SCPTu test (SCPTu 1)

\section{Conclusions}

This paper evaluated the interpretation of SCPTu tests conducted in a copper mining tailing deposit composed of a dry and a saturated layer. The copper tailing is a nonplastic silty grain-sized material and presents intermediate permeability, which caused partial drainage conditions during cone penetration on standard velocity. The influence of partial drainage on cone penetration tests was verified first on soil classification by SBT charts based on normalized cone measurements. It can be concluded that the cone tip resistance is more affected by partial drainage, which causes a reduction in this value and takes 
to inadequate material behavior classifications, indicating even a typical response of clayey soils in saturated layers.

The $G_{0} / q_{t}$ ratio seems to slightly reduce the dispersion of the data within the behavior assessment graph. However, some data corresponding to the saturated layer indicates an inappropriate behavior related to clayey soils.

The analysis in terms of friction angle did not indicate representative variations between the dry and saturated layers. However, a slight increase in $\mathrm{f}$ was observed in the saturated layers about the dry layers. It was found that the estimate based on direct correlations with $q_{t}$ values resulted in lower $\phi^{\prime}$ values.

The estimation of state parameter values was also evaluated, based on formulations developed for use in sands. It was found that for the dry layer and surface depths of saturated layer, the correlation provided values close to this defined in the laboratory. However, for greater depths of the saturated layer, an inconsistent estimation was found. Possibly the reduction in $q_{t}$ values caused by partial drainage led to higher $\psi$ values, demonstrating that the equation does not apply properly under these conditions.

It is concluded that the definition of design parameters in soils with partial drainage must be carried out with great caution, paying attention to test methodologies and interpretation of tests that take into account such effects.

\section{References}

1. IBRAM. (2018). Instituto Brasileiro de Mineração e Economia Mineral do Brasil. Report acess: http://portaldamineracao.com.br/wpcontent/uploads/2018/08/economiamineral-brasilset2018.pdf, acess in 10/09/2020.

2. IPEA. (2012). Instituto de Pesquisa Econômica Aplicada Diagnósticos dos Resíduos Sólidos Urbanos. Research report acess: http://ipea.gov.br/agencia/images/stories/PDFs/relat oriopesquisa/121009 relatorio residuos solidos ur banos.pdf, acess in 15/08/2020.

3. N. R. Morgenstern, S. G. Vick, C. B. Viotti, B. D. Watts. (2016). Fundão Tailings Dam Review Panel. Report on the Immediate Causes of the Failure of the Fundão Dam. August, 2016. Available from http://fundaoinvestigation.com/the-report/, acess in 6/10/2020.

4. P. K. Robetson, L. De Melo, D. J. Willians, G. W. Wilson. (2019). Report of the Expert Panel on the Technical Causes of the Failure of Feijão Dam I. Available from https://bdrblinvestigationstacc.z15.web.core.windo ws.net/assets/Feijao-Dam-I-Expert-Panel-ReportENG.pdf, acess in 10/10/2020.

5. T. W. Lambe, R. V. Whitman. (1969). Soil Mechanics. John Wiley and Sons.

6. F. Schnaid, B. M. Lehane, M. Fahey. (2005). In situ test characterization of unusual soils. In: Proc. of ISC-2 on Geotech. Geophys. Site Characterization. 1. 49-74.
7. G. Dienstmann, F. Schnaid, S. Maghous, J. Dejong. (2018). Piezocone Penetration Rate Effects in Transient Gold Tailings. Journal of Geotechnical and Geoenvironmental Engineering, 2018, $144: 2$, 04017116. DOI : $10.1061 /(A S C E) G T .1943-$ 5606.0001822

8. J. T. DeJong, M. F. Randolph. (2012). Influence of partial consolidation during cone penetration on estimated soil behavior type and pore pressure dissipation measurements. J. Geotech. Geoenviron. Eng. $\quad 138: 7, \quad 777-788 . \quad$ DOI: 10.1061/(ASCE)GT.1943-5606.0000646.

9. M. F. Randolph, S. N. Hope. (2004). Effect of cone velocity on cone resistance and excess pore pressure. In: Proc., Int. Symp. on Engineering Practice and Performance of Soft Deposits, Yodogawa Kogisha Co. Ltd., Osaka, Japan, 147-152.

10. K. Kim, M. Prezzi, R. Salgado, W. Lee. (2008). Effect of penetration rate on cone penetration resistance in saturated clayey soils. J. Geotech. Geoenviron. Eng., $134: 8,1142-1153$. DOI : 10.1061/(ASCE)1090-0241(2008)134:8(1142)

11. P. K. Robertson. (1990). Soil classification using the cone penetration test. Canadian Geotechnical Journal, 27 :1, 151-158. DOI : 10.1139/t90-014

12. P. K. Robertson, S. Sasitharan, J. C. Cunning, D. C. Segs. (1995). Shear wave velocity to evaluate flow liquefaction. Journal of Geotech. And Geoenv. Eng., $\begin{array}{llll}\text { ASCE, } & 121 & \text { (3): } 262-273 . & \text { DOI : }\end{array}$ 10.1061/(ASCE)0733-9410(1995)121:3(262)

13. T. Lunne, P. K. Robertson, J. J. M. Powell. (1997). Cone Penetration Testing in Geotechnical Practice. E \& FN Spon.

14. F. Schnaid. (2009). In Situ Testing in Geomechanics: the main tests. Taylor e Francis, London: 329p.

15. D. W. Hight, V. N. Georgiannou, C. J. Ford. (1994). Characterization of clayey sand. In: Proc. 7th Int. Conf. Of Offshore Structures, USA, 1:321-340.

16. F. Schnaid. (2005). Geocharacterisation and properties of natural soils by in situ tests. In: Proceedings of the International Conf. on Soil Mechanics and Geotech. Eng. AA Balkema Publishers, $16: 1,3$.

17. J. A. Schneider, R. E. S. Moss. (2011). Linking cyclic stress and cyclic strain based methods for assessment of cyclic liquefaction triggering in sands. Géotechnique Letters, 1: 31-36. DOI : 10.1680/geolett.11.00021.

18. P. K. Robertson. (2016). Cone Penetration Test (CPT)-Based Soil Behaviour Type (SBT) Classification System - An Update. Canadian Geotechnical Journal, 53: 1910-1927. DOI : 10.1139/cgj-2016-0044.

19. H. P. Nierwinski. (2019) Characterization and Geomechanical Behavior of Mining Tailings. D. Sc. Thesis Department of Civil Engineering, UFRGS, Porto Alegre, Brazil. 
20. M. D. Bolton. (1986). The strength and dilatancy of sands. Geotechnique. 36 :I, 65-78. DOI : 10.1680/geot.1986.36.1.65.

21. V. F. B. De Mello. (1971). The standard penetration test. Proc. 4th Pan American Conf. Soil Mechs. Found. Eng., San Juan Puerto Rico, ASCE, 1 : 1-86.

22. P. W. Mayne. (2006). Undisturbed sand strength from seismic cone tests. $2^{\text {nd }}$ James $K$. Mitchell Lectcure. J. Geomech. And Geoeng.,1 : 4, 249-256. DOI : $10.1080 / 17486020601035657$.

23. F. Schnaid, F., E. Odebrecht. (2012) Ensaios de campo e suas aplicações à Engenharia de Fundações. 2 ed. Oficina de Textos, São Paulo.

24. F. Schnaid, H. S. Yu. (2007). Interpretation of the seismic cone test in granular soils. Géotechnique, $57: 3,265-272$. 